\title{
Analisis Penerapan Sistem Manajemen Lingkungan terhadap Kinerja Lingkungan pada Rumah Sakit di Kota Bandung
}

Analysis of the implementation of environmental management system to environmental performance at hospitali in Bandung.

\author{
${ }^{1}$ Faizal Rachman, ${ }^{2}$ Nurleli, ${ }^{3}$ Yuni Rosdiana \\ ${ }^{1,2,3}$ ProdiAkuntansi, FakultasEkonomidanBisnis, Universitas Islam Bandung, \\ Jl. Tamansari No.1 Bandung 40116 \\ Email: ${ }^{1}$ faizal.rchmn71@gmail.com, ${ }^{2}$ lelinur@yahoo.com, ${ }^{3}$ yuni_sfajar@yahoo.com
}

\begin{abstract}
The environmental management system is part of the organizational management structure that anticipates the short-term and long-term impacts of products, services, and processes of the organizations that affect the environment. Organizations that implement a good environmental management system will have good environtmental performance. The purpose of this study is to determine the application of environmental management systems, environmental performance, and the impact of the implementation of environmental management systems on environmental performance at hospitals in Bandung. This research was conducted in 3 (three) hospitals in Bandung which is participant of PROPER 2015-2016, with research method used is descriptive analysis. The data sources used in this study are primary and secondary data, collected through a surveys of questionnaires and PROPER 2015-2016 ranks. The result showed that the implementation of environmental management system at hospitals in Bandung was good and environmental performance at 3 (three) hospitals in Bandung which is participant of PROPER 2015-2016 categorized into good criteria. Implementation of a good environmental management system will help the hospital to obtain a good environmental performance.
\end{abstract}

Keywords: Management Accounting, Environmental Management System, Environmental Performance, Hospital

Abstrak. Sistem manajemen lingkungan merupakan bagian dari struktur manajemen organisasi secara keseluruhan yang mengantisipasi dampak jangka pendek maupun jangka panjang dari produk, layanan, dan proses-proses dari organisasi yang mempengaruhi lingkungan hidup. Organisasi yang menerapkan sistem manajemen lingkungan yang baik akan memiliki kinerja lingkungan yang baik. Tujuan penelitian ini adalah untuk mengetahui penerapan sistem manajemen lingkungan, kinerja lingkungan, dan dampak penerapan sistem manajemen lingkungan terhadap kinerja lingkungan pada Rumah Sakit di Kota Bandung.Penelitian ini dilakukan di 3 (tiga) Rumah Sakit peserta PROPER 2015-2016 wilayah Kota Bandung dengan metode penelitian yang digunakan adalah metode analisis deskriptif. Sumber data yang digunakan dalam penelitian ini merupakan data primer dan sekunder yang dikumpulkan melalui survey kuesioner dan data peringkat PROPER tahun 2015-2016. Hasil penelitian menunjukan bahwa penerapan sistem manajemen lingkungan pada rumah sakit di Kota Bandung sudah baik, dan kinerja lingkungan pada 3 (tiga) rumah sakit peserta PROPER 2015-2016 di Kota Bandung termasuk dalam kriteria baik. Penerapan sistem manajemen lingkungan yang baik akan membantu pihak rumah sakit untuk memperoleh kinerja lingkungan yang baik. 


\section{Kata Kunci:Akuntansi Manajemen, Sistem Manajemen Lingkungan, Kinerja Lingkungan, Rumah Sakit}

\section{A. Pendahuluan}

Pencemaran lingkungan meningkat seiring dengan bertambahnya jumlah penduduk dan beraneka ragamnya industri. Para pelaku industri kadang mengesampingkan pengelolaan lingkungan yang menghasilkan berbagai limbah dan sampah. Rumah sakit sebagai organisasi pelayanan kesehatan harus memperhatikan masalah lingkungan, karena dapat dikatakan rumah sakit merupakan pendonor limbah sebagai bentuk buangan yang berasal dari kegiatan medis dan non-medis yang bersifat berbahaya dan beracun (Nadia Paramita, 2007).

Menurut Undang-undang Republik Indonesia Nomor 32 Tahun 2009 tentang perlindungan dan pengelolaan lingkungan, dinyatakan bahwa perlindungan dan pengelolaan lingkungan hidup adalah upaya sistematis dan terpadu yang dilakukan untuk mencegah terjadinya pencemaran dan/atau kerusakan lingkungan hidup yang meliputi perencanaan, pemanfaatan, pengendalian, pemeliharaan, pengawasan, dan penegakan hukum. Sehingga rumah sakit perlu memberikan perhatian khusus terhadap pencemaran lingkungan yang bersumber dari limbah rumah sakit, yang bertujuan untuk melindungi masyarakat dan petugas rumah sakit itu sendiri (Darmadi, 2008).

Berdasarkan data Program Penilaian Peringkatan Kinerja Perusahaan dalam Pengelolaan Lingkungan Hidup Daerah (Properda) Kota Bandung, terdapat 9 rumah sakit yang mengikuti PROPERDA, namun 3 diantaranya memperoleh peringkat merah yaitu RSIA Limijati, RS Advent, dan RS Immanuel (BPLHD Kota Bandung). Peringkat merah yang didapatkan oleh ke-tiga rumah sakit tersebut menunjukan bahwa upaya yang dilakukan pihak rumah sakit dalam pengelolaan lingkungan belum sesuai dengan standar yang berlaku.

Pada saat ini kinerja lingkungan menjadi salah satu aspek pengukur kinerja suatu organisasi mengingat adanya PROPER yaitu Program Penilaian Peringkat Kinerja Perusahaan Dalam Pengelolaan Lingkungan yang dikembangkan oleh Kementerian Lingkungan Hidup sejak tahun 1995 untuk mendorong perusahaan meningkatkan pengelolaan lingkungannya, namun tidak tertutup kemungkinan bahwa suatu organisasi mengabaikan isu lingkungan tersebut. Limbah rumah sakit yang beracun dapat menyebabkan atau menularkan penyakit pada manusia dan kerusakan pada elemen lingkungan lainnya.

Meningkatnya tuntutan dan kesadaran masyarakat global akan lingkungan telah mendorong para pelaku industri untuk menerapkan sistem manajemen lingkungan atau Environmental Management System (EMS).

Berdasarkan uraian pada latar belakang diatas maka penulis memfokuskan penelitiannya berkaitan dengan:

1) Bagaimana penerapan sistem manajemen lingkungan pada Rumah Sakit di Kota Bandung?

2) Bagaimana kinerja lingkungan Rumah Sakit di Kota Bandung ?

3) Bagaimana penerapan sistem manajemen lingkungan dalam kaitannya dengan kinerja lingkungan pada Rumah Sakit di Kota Bandung?

Selanjutnya tujuan dari penelitian ini adalah:

1) Untuk mengetahui bagaimana penerapan sistem manajemen lingkungan pada Rumah Sakit di Kota Bandung

2) Untuk mengetahui bagaimana kinerja lingkungan pada Rumah Sakit di 
Kota Bandung

3) Untuk memahami penerapan sistem manajemen lingkungan dalam kaitannya dengan kinerja lingkungan pada Rumah Sakit di Kota Bandung

\section{B. Landasan Teori}

Dalam bagian ini akan dibahas mengenai teori-teori yang berkaitan dengan masing-masing objek penelitian yang akan diteliti dalam penelitian ini. Teori-teori tersebut merupakan sebuah pondasi dalam penentuan kerangka pemikiran dalam sebuah penelitian. Berikut merupakan landasan teori yang akan dikaji.

\section{Teori Legitimasi}

Teori Legitimasi berasal dari konsep legitimasi organisasi yang diungkapkan oleh Dowling \& Pfeffer (1975) yang mengungkapkan bahwa legitimasi adalah sebuah kondisi atau status yang ada ketika sistem nilai entitas kongruen dengan sistem nilai masyarakat yang lebih luas di tempat entitas tersebut berada. Ketika terjadi suatu perbedaan, baik yang nyata ataupun berpotensi muncul di antara kedua sistem nilai tersebut, maka akan muncul ancaman terhadap legitimasi entitas. Sesuai dengan yang dinyatakan O'Donovan (2002) bahwa legitimasi merupakan gagasan agar sebuah organisasi dapat terus beroperasi dengan sukses, maka organisasi tersebut harus bertindak sesuai aturan yang diterima secara luas oleh masyarakat. Deegan (2002) menyatakan bahwa teori legitimasi adalah sebagai:

Teori yang menyatakan bahwa organisasi secara berkelanjutan mencari cara untuk menjamin operasi mereka berada dalam batas dan norma yang berlaku di masyarakat. Suatu perusahaan akan secara sukarela melaporkan aktivitasnya jika manajemen menganggap bahwa hal ini adalah yang diharapkan komunitas.

Ghozali \& Chariri (2007) dalam Lindawati \& Puspita (2015) menyatakan bahwa hal yang mendasari teori legitimasi adalah kontrak sosial antar perusahaan dan masyarakat di tempat perusahaan beroperasi dan menggunakan sumber ekonomi. Jadi, setiap perusahaan memiliki kontrak implisit dengan masyarakat untuk melakukan aktivitasnya berdasarkan nilai-nilai yang dijunjung dalam masyarakat. Apabila perusahaan bertindak memenuhi kontrak implisit maka masyarakat akan mendukung keinginan perusahaan tersebut.

\section{Kinerja Lingkungan}

Kinerja lingkungan adalah hasil yang dapat diukur dari sistem manajemen lingkungan, yang terkait dengan kontrol aspek-aspek lingkungannya, serta pengkajian kinerja lingkungan yang didasarkan pada kebijakan lingkungan, sasaran lingkungan dan target lingkungan (ISO 14004, dari ISO 14001, 2004). Menurut Ikhsan (2008), kinerja lingkungan adalah aktivitas-aktivitas yang dilakukan perusahaan yang terkait langsung dengan lingkungan alam sekitarnya. Menurut Bawley dan Li (2000) di dalam Clarkson (2006) kinerja lingkungan adalah: "proxied by their industry membership and by whether they report to the Ministry of Environment under the National Pollution Release Inventory program". Jadi dengan demikan kinerja lingkungan (environmental performance) ialah seluruh kegiatan dan aktivitas perusahaan yang memperlihatkan kinerja perusahaan dalam menjaga lingkungan sekitarnya serta melaporkannya kepada pihak yangberkepentingan.

Menurut Purwanto (2000), kinerja lingkungan dapat diukur dengan dua cara, yaitu: 

1. Kinerja lingkungankualitatif.

Ukuran yang didasarkan pada penilaian semantik, pandangan, persepsi seseorang berdasarkan pengamatan dan penilaiannya terhadap sesuatu. Keuntungan dari metrik ini adalah pengumpulan datanya relatif mudah dilakukan dan mudah diimplementasikan. Kerugiannya adalah metrik ini secara implisit melibatkan subyektifitas dan karenanya sulit divalidasi.

2. Kinerja lingkungankuantitatif.

Ukuran yang didasarkan pada data empiris dan hasil numerik yang mengkarakteristikkan kinerja dalam bentuk fisik, keuangan, atau bentuk lain. Contohnya adalah batas baku mutu limbah. Keuntungan dari metrik ini adalah objektif, sangat berarti, dan dapat diverifikasi. Kerugiannya adalah data yang diperlukan mungkin sulit diperoleh.

3. Kinerja lingkungan kualitatif

Hasil dapat diukur dari hal-hal yang terkait dengan ukuran aset non fisik, seperti prosedur, proses inovasi, motivasi, dan semangat kerja yang dialami pelaku kegiatan, dalam mewujudkan kebijakan lingkungan organisasi, sasaran dan targetnya. Kinerja lingkungan kuantitatif adalah hasil yang dapat diukur dari sistem manajemen lingkungan yang terkait kontrol aspek lingkungan fisiknya (Purwanto, 2000).

\section{Sistem Manajemen Lingkungan}

Pengertian sistem manajemen lingkungan menurut ISO 14001:2004 merupakan suatu sistem manajemen pengelolaan lingkungan yang telah diakui secara internasional dengan sertifikat yang dikeluarkan oleh Badan Sertifikat dibawah koordinasi International Standard Organization (ISO).Sistem manajemen lingkungan atau Environtment Management System (EMS) adalah bagian dari keseluruhan sistem manajemen yang meliputi struktur organisasi, rencana kegiatan, tanggung jawab, pelatihan atau praktek, prosedur, proses dan sumber daya untuk pengembangan, penerapan, evaluasi dan pemeliharaan kebijakan lingkungan (ISO 14001, 2004).

Sistem Manajemen Lingkungan (SML) menurut Tibor dan Feldman (1997) merupakan bagian dari suatu sistem manajemen yang meliputi struktur organisasi, perencanaan kegiatan, tanggung jawab, praktek prosedur, proses dan sumber daya untuk mengembangkan, melaksanakan, mencapai, mengkaji dan memelihara kebijakan lingkungan (Tibor dan Feldman, 1997). Berdasarkan penjelasan diatas dapat ditarik kesimpulan bahwa sistem manajemen lingkungan merupakan sistem manajemen yang berkaitan dengan kebijakan perusahaan yang berpotensi memberikan dampak bagi lingkungan operasi perusahaan, dimana sistem manajemen tersebut harus meliputi keseluruhan proses mulai dari perncanaan, penelitian, penerapan, pertanggungjawaban, peninjauan ulang serta pemeliharan kebijakan yang telah dihasilkan.

Organisasi atau perusahaan yang akan menerapkan (Sistem Manajemen Lingkungan) SML perlu mempersiapkan hal-hal sebagai berikut (Standar Nasional Indonesia (SNI) 19-14001, 2005).

1. Kebijakan Lingkungan.

Menurut ISO 14001:2015 kebijakan lingkungan adalah dokumen yang didalamnya memuat maksud dan arahan suatu organisasi terkait dengan kinerja lingkungan organisasi tersebut sebagaimana dinyatakan secara resmi oleh manajemen puncak. Manajemen puncak harus menetapkan kebijakan 

lingkungan organisasi dan memastikan bahwa kebijakan lingkungan dikomunikasikan kepada semua orang yangbekerja atas nama organisasi dan mencakup komitmen pada perbaikan berkelanjutan dan pencegahan pencemaran.

2. Perencanaan

Perencanaan merupakan salah satu komponen penting karena apabila gagal membuat perencanaan akan mengalami kendala dalam melakukan kegiatan selanjutnya. Hal-hal yang perlu diperhitungkan pada saat membuat perencanaan lingkungan yaitu persyaratan-persyaratan legal, identifikasi aspek lingkungan, tujuan, sasaran, dan program lingkungan.

3. Penerapan dan Operasi

Bila rumah sakit mengharapkan pelaksanaan program lingkungannya dengan baik, rumah sakit harus mengembangkan kemampuan untuk mendukung sistem manajemen lingkungan tersebut. Pelaksanaan sistem manajemen lingkungan harus memperhatikan hal-hal seperti struktur tanggungjawab, dokumentasi dan komunikasi yang berkaitan dengan aspek lingkungan, dan pengendalian dokumen guna memfasilitasi manajemen lingkungan yang efektif.

4. Pemeriksaan

Program-program yang telah dibuat dalam perencanaan tersebut akan dievaluasi secara berkala melalui program audit lingkungan. Saat diaudit semua program yang sudah dituliskan akan dievaluasi dan dilihat di lapangan apakah program yang dibuat dilaksanakan atau tidak. Program-program yang belum dilaksanakan akan dipertanyakan alasan-alasan yang menyebabkan tidak terlaksananya program tersebut. Disamping itu dalam audit lingkungan dapat diketahui apabila terjadi penyimpangan-penyimpangan dalam pelaksanaan program tersebut.

5. Tinjauan Manajemen

Manajemen puncak harus meninjau sistem manajemen lingkungan organisasi pada jangka waktu tertentu, untuk memelihara kesesuaian, kecukupan dan efektivitas sistem yang berkelanjutan. Tinjauan harus termasuk mengkaji kesempatan untuk perbaikan dan keperluan untuk melakukan perubahan pada sistem manajemen lingkunganm termasuk kebijakan lingkungan, tujuan, sasaran, dan program lingkungan.

Gambar 2.1.Model SitemManajemenLingkungan

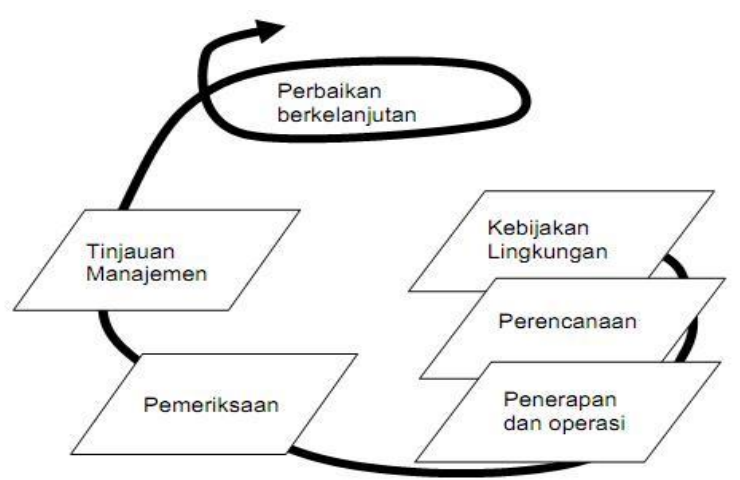

Sumber: SNI 19-14001-2005 

Berbagai manfaat dapat diperoleh bila perusahaan menerapkan ISO 14001 yang sekaligus dapat dianggap sebagai keuntungan dari manajemen lingkungan. Manfaat yang paling penting adalah perlindungan lingkungan.

Program ini bukan hanya melestarikan sumber daya alam namun dapat pula menghemat biaya operasi (Hadiwiardjo, 1997 dalam Ramadhanti, 2013). Manfaat yang didapatkan suatu perusahaan dengan diterapkannya ISO 14001 adalah:

1. Perlindungan lingkungan

2. Manajemen lingkungan yang lebih baik

3. Mempertinggi daya saing

4. Menjamin ketaatan terhadap peraturan perundang-undangan

5. Penerapan sistem menajemen yang efektif

6. Pengurangan Biaya

7. Hubungan Masyarakat yang lebih baik

8. Kepercayaan dan kepuasan langganan yang lebih baik.

\section{Metode Penelitian}

Metode penelitian yang digunakan dalam penelitian ini adalah metode deskriptif analitis dengan pendekatan kuantitatif. Penelitian ini menjelaskan gambaran tentang fenomena yang terjadi di dunia nyata dengan sejelas-jelasnya. Penelitian ini dilakukan pada RS Hasan Sadikin, RS Adventdan RS Santosa. Teknik pengumpulan data dilakukan dengan menggunakan kuesioner dan wawancara. Kuesioner terdiri dari beberapa pernyataan tertutup. Kemudian hasil dari tanggapan responden diolah dan menghasilkan informasi berupa analisis statistik deskriptif.

\section{Hasil Penelitian danPembahasan}

Penerapan Sistem Manajemen Lingkungan (X) dalam Kaitannya dengan Kinerja Lingkungan ( $\mathbf{Y})$

Pada penelitian ini, teknik analisis data yang digunakan adalah teknik analisis deskriptif dengan metode kualitatif. Berikut merupakan hasil tanggapan responden melalui kuesioner penelitian mengenai analisis penerapan sistem manajemen lingkungan terhadap kinerj lingkungan.

Tabel 1

Hasil Tanggapan Responden Mengenai Sistem Manajemen Lingkungan

\begin{tabular}{|l|c|c|c|}
\hline \multicolumn{1}{|c|}{ Dimensi } & Skor & Presentasi Skor & Kriteria \\
\hline Kebijakan Lingkungan & 436 & $68,125 \%$ & Baik \\
\hline Perencanaan Lingkungan & 557 & $69,625 \%$ & Baik \\
\hline Penerapan dan Operasi & 811 & $72,41 \%$ & Baik \\
\hline Pemeriksaan & 545 & $68,125 \%$ & Baik \\
\hline Tinjauan Manajemen & 460 & $71,875 \%$ & Baik \\
\hline Total & 2.089 & $70,22 \%$ & Baik \\
\hline
\end{tabular}

Sumber: HasilPerhitungan 



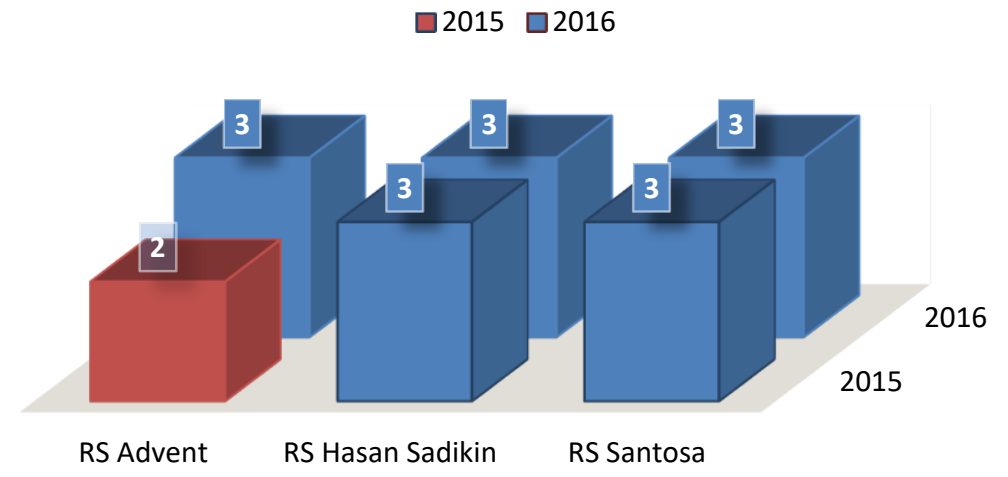

Sumber: Data PROPER 2015-2016 DinasLingkunganHidup Kota Bandung

Gambar 2. Diagram Kinerja Lingkungan

Dari tabel di atas, dapat diketahui bahwa besarnya persentase skor responden mengenai penerapan sistem manajemen lingkungan sebesar 70,22\%. Nilai persentase skor tersebut termasuk kedalam kategori baik menurut tabel kriteria. Hal tersebut menunjukan bahwa penerapan sistem manajemen lingkungan yang dilakukan oleh pihak rumah sakit sudah baik. Sistem manajemen lingkungan dalam penelitian ini meliputi kebijakan lingkungan, perencanaan lingkungan, penerapan dan operasi, pemeriksaan, dan tinjauan manajemen. Sedangkan kinerja lingkungan meliputi hasil peringkat PROPER 2015-2016 yaitu emas, hijau, biru, merah, dan hitam.

Hasil dari penelitian terlihat bahwa rumah sakit yang menerapkan sistem manajemen lingkungan dengan baik akan mampu memperbaiki kinerja lingkungan rumah sakit tersebut. Dapat dilihat pada Gambar 2, bahwa berdasarkan penilaian yang dilakukan oleh Dinas Lingkungan Hidup Kota Bandung, Rumah Sakit Advent memperoleh peringkat merah pada tahun 2015, namun pada tahun 2016 Rumah Sakit Advent memperoleh peringkat biru. Hal tersebut menunjukan bahwa penerapan sistem manajemen lingkungan memberikan dampak jangka pendek ataupun jangka panjang terhadap kinerja lingkungan.

Jika unsur-unsur penerapan sistem manajemen lingkungan yakni kebijakan lingkungan, perencanan lingkungan, penerapan dan operasi sistem manajemen lingkungan, pemeriksaan dan tinjauan manajemen sudah dilakukan dengan baik akan memberikan dukungan terhadap pelaksanaan kegiatan pengelolaan limbah dan pemeliharan lingkungan hidup sesuai dengan ketentuan perundang-undangan. Maka dapat dikatakan bahwa secara keseluruhan, penerapan sistem manajemen lingkungan yang diterapkan dengan baik akan memberikan dampak pada peningkatan kinerja lingkungan.

\section{E. Kesimpulan dan Saran \\ Kesimpulan}

Berdasarkan pembahasan dalam penelitian ini, peneliti menyimpulkan beberapa hasil penelitian sebagai berikut:

1. Penerapan sistem manajemen lingkungan pada 3 (tiga) rumah sakit peserta PROPER 2015-2016 sudah baik, hal ini ditunjukan dengan penerapan kebijakan 

lingkungan, perencanaan lingkungan, pelaksanaan dan pemeriksaan sistem manajemen lingkungan, serta tindakan evaluasi yang dilakukan oleh pihak manajemen sudah baik.

2. Rumah sakit di Kota Bandung yang mengikuti PROPER 2015-2016 rata-rata telah memperoleh peringkat biru, hal tersebut menandakan bahwa kinerja lingkungan rumah sakit di Kota Bandung sudah baik dan sesuai dengan peraturan perundang-undangan yang berlaku.

3. Perusahaan atau organisasi yang menerapkan sistem manajemen lingkungan dengan baik maka akan meningkatkan kinerja lingkungan kearah yang lebih baik.

\section{Saran}

1. Ketiga rumah sakit peserta PROPER 2015-2016 diharapkan dapat memperbaiki penerapan kebijakan lingkungan dan pemeriksaan sistem manajemen lingkungan oleh pihak manajemen, karena dukungan manajemen puncak sangat penting dalam membentuk dan menjalankan sistem manajemen lingkungan agar efektif.

2. Rumah Sakit yang sudah memiliki sistem manajemen lingkungan yang baik dan memperoleh peringkat biru, diharapkan dapat meningkatkan upaya pengelolaan lingkungan dalam hal minimalisasi konsentrasi air limbah, emisi udara, dan pengelolaan limbah B3 agar memperoleh peringkat hijau atau emas dalam kinerja lingkungannya.

\section{F. Daftar Pustaka}

Clarkson, Peter M., Michael B. Overell, dan Larelle Chapple. Environmental Reporting its Relation to Corporate Environmental Performance. A Journal of Accounting, Finance and Business Studies 47(1):27-60.

Darmadi. 2008. Infeksi Nonsomikal Problematika \& Pengendaliannya. Jakarta: Salemba Medika.

Deegan, Craig. 2002. Introduction: The Legitimising Effect of Social and Environment Disclosures - A Theoretical Foundation. Accounting, Auditing, \&Accountability Journal 15(3): 282-311

Dowling, John, dsn Jeffrey Pfeffer. 1975. Organizational Legitimacy: Social Values and Organizational Behaviour. The Pacific Sociological Review 18(1): 122-136

International Organization for Standardization. 2004. ISO 14001 Environmental Management Systems: Requirement with Guidance for Use. International Standard.

Ikhsan, Arfan. 2008. Akuntansi Manajemen Lingkungan. Yogyakarta: Graha Ilmu.

Lindawati, Ang Swat Lin, dan Marsella Eka Puspita. 2015. Corporate Social Responsibility: Implikasi Stakeholder dan Legitimacy Gap dalam Peningkatan Kinerja Perusahaan. Jurnal Akuntansi Multiparadigma JAMAL 6(1): 157-174

O'Donovan, Gary. 2002. Environmental Disclosure in the Annual Report: Extending the Applicability and Predictive Power of Legitimacy Theory. Accounting, Auditing \& Accountability Journal 15(3): 344-371

Paramita, Nadia. 2007. Evaluasi Pengelolaan Sampah Rumah Sakit Pusat Angkata Darat Gatot Subroto. Skripsi. Semarang: Universitas Diponegoro. 

Purwanto, Andie T. 2000. Pengukuran Kinerja Lingkungan (andipt2000@yahoo.com) di akses pada tanggal 20 April 2016.

Ramadhanti, F. 2013. Panduan Penerapan Sistem Manajemen Lingkungan.

Republik Indonesia. 2009. Undang-Undang No. 32 Tahun 2009 tentang Perlindungan dan Pengelolaan Lingkungan Hidup. Jakarta: Sekertariat Negara.

Tibor dan Feldman. 1997. Sistem Manajemen Lingkungan.

Undang-undang Republik Indonesia Nomor 32 Tahun 2009 tentang Perlindungan dan Pengelolaan Lingkungan 